\title{
In Vitro Antifungal Potency of Plant Extracts Against Five Phytopathogens
}

\author{
Ashwani Tapwal ${ }^{1 *}$ Nisha $^{2}$, Shipra Garg ${ }^{2}$, Nandini Gautam ${ }^{2}$ and Rajesh Kumar ${ }^{1}$ \\ ${ }^{1}$ Rain Forest Research Institute; P.B. 136, 78500; Deovan, Jorhat, Assam - India. ${ }^{2}$ Shoolini Institute of Life \\ Sciences and Business Management; Anand Campus, The Mall Solan, HP - India
}

\begin{abstract}
The antifungal activity of aqueous extract of Cannabis sativa, Parthenium hysterophorus, Urtica dioeca, Polystichum squarrosum and Adiantum venustum was investigated against Alternaria solani, Alternaria zinniae, Curvularia lunata, Rhizoctonia solani and Fusarium oxysporum at different concentrations (5, 10, 15 and 20\%). At 20\%, maximum antifungal potential was observed with the extracts of $\mathrm{C}$. sativa, which recorded excellent inhibitory activity against C. lunata (100\%), A. zinniae (59.68\%), followed by leaf extract of $\mathrm{P}$. hysterophorus (50\%) against A. solani. The application of botanical extracts for disease management could be less expensive, easily available, non-polluting and eco-friendly.
\end{abstract}

Key words: Botanical, phytoextract, antifungal, phytopathogen, IPM

\section{INTRODUCTION}

Plants are the major source of food, fibre, fodder, medicines and many other useful products for mankind. Different plant parts such as roots, stem, leaves, fruits, flowers/inflorescence and seeds are utilized for day-to-day requirements of the human beings. Various insects, bacteria, viruses, fungi and other pests attack the plants at the various stages of their development. It reduces their productivity and leads to a huge loss to mankind.

More than 800 million people in the developing countries do not have adequate food supplies and at least $10 \%$ of food is lost due to plant diseases (Strange and Scott, 2005). As compared to other plant parasites, fungi cause the greatest impact with regard to diseases and crop production losses. The most important method of protecting the plants against the fungal attack is the use of fungicides. However, many fungicidal agents available in the market are toxic and have undesirable effects on other organisms present in the environment. Some synthetic fungicides are non-biodegradable, and hence can accumulate in the soil, plants and water, and consequently effect the humans through the food chain. The development of resistance of pathogenic fungi towards the synthetic fungicides is of great concern. Therefore, it is desirable to use some ecofriendly measures for the management of diseases. Many of the earlier pesticides were the extracts of plants, and several plants have been exploited more widely as sources of commercial insecticides. But, from 1940s, synthetic agrochemicals largely replaced the plant-derived products as the key commercial pesticides.

*Author for correspondence: ashwanitapwal@gmail.com 
Research on plant-derived natural products for the use in agriculture went into decline for a number of years. But this trend is now reversed as it becomes evident that plant natural products still have enormous potential to inspire and influence the modern agrochemical research (Choi et al., 2004).

Natural products seem to be a viable solution to the environmental problems caused by the synthetic pesticides and many researchers are trying to identify the effective natural products to replace the synthetic pesticides (Kim et al., 2005). The presence of antifungal compounds in higher plants has long been recognized as an important factor in disease resistance (Mahadevan, 1982). Such compounds, being biodegradable and selective in their toxicity, are considered valuable for controlling some plant diseases (Singh and Dwivedi, 1987).

Although there is a growing interest in the use of medicinal plants to control the plant diseases, only about 2,400 plant species among more than 250,000 higher plants have been screened for the phytoactivity (Oluwalana and Adekunle, 1998; Oluwalana et al., 1999; Khafagi and Dewedar, 2000). The plant based pesticides are cheap, locally available, non-toxic, easily biodegradable. There are evidences from earlier works that several plant species possess antifungal and antibacterial properties (Manoharachary and Gourinath, 1988; Bandara et al., 1989; Srivastava and Lal, 1997; Maji et al., 2005; Nduagu et al., 2008; Yasmin et al., 2008; Harlapur et al., 2007 and Akinbode and Ikotun, 2008).

Plant metabolites and plant based pesticides appear to be one of the better alternatives in plant disease management, as they are known to have minimal harmful impact on the environment and danger to consumers in contrast to the synthetic pesticides (Varma and Dubey, 1999). Therefore, the present investigation was undertaken to screen the crude extracts of five plants for their antifungal potency in laboratory conditions against important phytopathogenic fungi, i.e., Alternaria solani, Alternaria zinniae, Fusarium oxysporum, Rhizoctonia solani and Curvularia lunata. Out of selected five plants species, two belonged to pteridophytes (Polystichum squarrosum, Adiantum venustum) and rest of three plants were weeds/ medicinal plant species (Parthenium hysterophorus, Urtica dioeca and Cannabis sativa).

\section{MATERIAL AND METHODS}

Selected plant species were collected from the undisturbed habitats of Solan district, Himachal Pradesh (India). Pure cultures of pathogen were collected from the Department of Botany, Shoolini Institute of Life Sciences and Management, Solan, Himachal Pradesh. Potato Dextrose Agar (PDA) was used as medium for sub-culturing the microbes.

\section{Extraction and evaluation of the plant materials}

Fresh leaves of healthy plants were collected and washed thoroughly with tap water and air dried. One hundred grams of plant tissue was ground using pestle and mortar by adding equal amount $(100 \mathrm{ml})$ of sterilized distilled water $(1: 1, \mathrm{w} / \mathrm{v})$. The pulverized mass was squeezed through the cheese cloth and the extracts were centrifuged at $10000 \mathrm{rpm}$ for $5-10$ minutes. The supernatant was filtered through Millipore filters $(45 \mu \mathrm{m})$ using vacuum pump assembly under aseptic conditions. A requisite amount of the filtrate was mixed in PDA just before pouring to get the desired concentrations of 5, 10, 15 and $20 \%$ and gently shaken for thorough mixing of the extract. The PDA plates containing the plant extracts were inoculated aseptically with the pathogen by transferring five $\mathrm{mm}$ diameter agar disc from the fresh cultures. Three replications were maintained for each treatment. The basal medium (PDA) without any phytoextract served as the control. All the inoculated Petri dishes were incubated at $25 \pm 1^{\circ} \mathrm{C}$. The radial growth of the test fungus was measured in all the treatments after three days and compared with the control. The per cent inhibition of fungal growth was estimated by using following formula (Vincent, 1927):

$$
I=\frac{\mathrm{C}-\mathrm{T}}{\mathrm{C}} \times 100
$$

Where, $\mathrm{I}=$ per cent inhibition

$\mathrm{C}=$ Colony diameter in control

$\mathrm{T}=$ Colony diameter in treatment

The data was recorded in triplicates and subjected to statistical analysis and conclusions were drawn on the basis of analysis of variance. The calculated value of $\mathrm{F}$ was compared with the tabulated values at 5\% level of significance for an appropriate degree of freedom. 


\section{RESULT AND DISCUSSIONS}

Natural products with pesticidal activity are being explored in order to make available the pesticides, which are easily biodegradable, selective and can be locally produced, especially for the farmers who cannot afford expensive synthetic pesticides. The results revealed that all of the tested plant extracts at each concentration inhibited the growth of pathogens (Table 1). The rate of growth inhibition was corroborated with its concentrations in case of all the tested plant extracts. It was observed that at $20 \%$ concentration of leaf extract, Cannabis was most effective to inhibit the mycelial growth, followed by Parthenium, Urtica, Adiantum and Polystichum was least effective. By using the weeds/invasive plant species as raw material for plant-derived fungicides, one could can manage the disease, and at the same time might create economic uses for these unwanted species.

Table-1 In vitro growth inhibition of phytopathogens by the leaf extract of different plants.

\begin{tabular}{|c|c|c|c|c|c|c|}
\hline \multirow{2}{*}{ Pathogen } & \multirow{2}{*}{$\begin{array}{c}\text { Conc. of } \\
\text { Phyto-extract }\end{array}$} & \multicolumn{5}{|c|}{ Growth inhibition (\%) at different concentration of leaf extract } \\
\hline & & C. sativa & P. hysterophorus & U. dioeca & A. venustum & P. squarrosum \\
\hline \multirow[t]{4}{*}{ A. solani } & $5 \%$ & 31.01 & 8.33 & 20.83 & 4.76 & 13.60 \\
\hline & $10 \%$ & 38.02 & 16.67 & 29.17 & 15.07 & 18.40 \\
\hline & $15 \%$ & 43.68 & 37.50 & 37.50 & 19.44 & 25.60 \\
\hline & $20 \%$ & 53.53 & 50.00 & 41.67 & 23.81 & 32.80 \\
\hline \multicolumn{7}{|c|}{$\mathrm{SEm} \pm=0.61, \mathrm{CD}(\mathrm{p}=0.05)=1.84$} \\
\hline \multicolumn{7}{|l|}{ A. zinniae } \\
\hline & $5 \%$ & 43.55 & 11.43 & 12.99 & 22.37 & 19.72 \\
\hline & $10 \%$ & 50.00 & 21.43 & 18.18 & 26.32 & 26.76 \\
\hline & $15 \%$ & 56.45 & 27.14 & 27.27 & 30.26 & 30.99 \\
\hline & $20 \%$ & 59.68 & 38.57 & 29.87 & 40.79 & 36.62 \\
\hline \multicolumn{7}{|c|}{$\mathrm{SEm} \pm=0.72, \mathrm{CD}(\mathrm{p}=0.05)=2.16$} \\
\hline \multicolumn{7}{|l|}{ C. lunata } \\
\hline & $5 \%$ & 36.28 & 1.52 & 25.00 & 2.50 & 0.00 \\
\hline & $10 \%$ & 40.71 & 6.06 & 38.19 & 4.17 & 22.46 \\
\hline & $15 \%$ & 100.00 & 9.85 & 41.67 & 9.17 & 35.51 \\
\hline & $20 \%$ & 100.00 & 13.64 & 47.92 & 19.17 & 39.86 \\
\hline \multicolumn{7}{|c|}{$\mathrm{SEm} \pm=1.38, \mathrm{CD}(\mathrm{p}=0.05)=4.14$} \\
\hline \multicolumn{7}{|l|}{ R. solani } \\
\hline & $5 \%$ & 33.10 & 3.82 & 3.01 & 1.63 & 2.61 \\
\hline & $10 \%$ & 40.00 & 12.10 & 7.52 & 4.07 & 12.17 \\
\hline & $15 \%$ & 43.45 & 23.57 & 9.77 & 8.94 & 14.78 \\
\hline & $20 \%$ & 47.59 & 33.12 & 18.80 & 10.57 & 24.35 \\
\hline \multicolumn{7}{|c|}{$\mathrm{SEm} \pm=0.79, \mathrm{CD}(\mathrm{p}=0.05)=2.38$} \\
\hline \multicolumn{7}{|c|}{ F. oxysporum } \\
\hline & $5 \%$ & 23.47 & 9.82 & 11.54 & 21.90 & 8.74 \\
\hline & $10 \%$ & 34.69 & 11.61 & 14.42 & 25.71 & 21.36 \\
\hline & $15 \%$ & 42.86 & 12.50 & 16.35 & 26.67 & 27.18 \\
\hline & $20 \%$ & 47.96 & 20.54 & 20.19 & 32.38 & 33.01 \\
\hline
\end{tabular}

C. sativa, commonly known as cannabis is the earliest food, fibre, medicinal, psychoactive and oil yielding cultivated plant and for centuries, it, has been ranked as one of the most important agricultural crops. Due to its sedative and psychoactive properties, its cultivation is prohibited by the government and now it exists in wild only. The leaf extract of Cannabis was most 
effective to restrict the growth of all the pathogens. At $20 \%$ concentration, $100 \%$ growth inhibition was recorded against $C$. lunata, followed by $A$. zinniae $(59.68 \%), \quad A$. solani $(53.53 \%), \quad F$. oxysporum $(47.96 \%)$ and minimum $47.59 \%$ for $R$. solani. The insecticidal and antimicrobial properties of the cannabis have also been reported in the literature (Roy and Dutta, 2003; Bajwa and Ramzan, 2004).

Next to Cannabis, it was the leaf extract of Parthenium which recorded 50\% growth inhibition against $A$. solani, followed by A. zinniae (38.57\%), R. solani $(33.12 \%), F$. oxysporum $(20.54 \%)$ and minimum $13.64 \%$ against $C$. lunata. Similar findings on antifungal and nematicidal nature of parthenium were documented by Bajwa et al. (2004) and Sharma and Trivedi (2002). Parthenium is a noxious weeds weed commonly known as congress grass. It aggressively colonizes the disturbed sites and reduces the pasture growth and depresses the forage production. Because of its invasive capacity and allelopathic properties, it has the potential to disrupt the natural ecosystems. Another indirect effect of the presence of parthenium weed is its potential role as an alternate host for the crop pests, functioning as an inter-season reservoir or inoculum source. For example, it hosts the scarab beetle pest of sunflower (Pseudoheteronyx sp.) in the central Queensland (Robertson and Kettle, 1994) and plant parasitic nematodes in the USA (Navie et al., 1996). Hence, by utilizing this weed in the plant disease management, one could protect the land from its invasion as well as get some economic gains by disease control.

Urtica restricts the growth of pathogen between $18.80-47.92 \%$ as compared to the control at $20 \%$ concentration leaf extract. Maximum growth inhibition by Urtica was recorded for $C$. lunata (47.92\%), followed by A. solani (41.67\%), A. zinniae (29.87\%), F. oxysporum (20.19\%) and minimum $18.80 \%$ against $R$. solani. $U$. dioica, commonly called as stinging nettle, is a perennial herbaceous plant found in temperate and tropical wasteland areas. It can form large colonies in the orchards, farmyards, old pastures, ditches, and waste places. The stinging hairs readily break, allowing the secretions to enter the skin. Nettle can be a very dangerous plant because, when the skin touches hairs and bristles on the leaves and stems, it gives a terrible sting, which is very painful. The stinging sensation is caused due to the action of some plant chemicals such as formic acid, histamine, serotonin and choline. Antimicrobial potency of Urtica has been also reported by Hadizadeh, et al. (2009) and Patni and Kolte (2006) on variety of pathogens.

Among the pteridophytes, the phytoextract of Adiantum was more efficient as compared to Polystichum. Maximum mycelial growth inhibition of $40.79 \%$ was recorded by the leaf extract of Adiantum against A. zinnia, followed by F. oxysporum (32.38\%), A. solani $(23.81 \%), C$. lunata $(19.17 \%)$ and minimum $10.57 \%$ against $R$. solani. The extract of Polystichum was most effective against $C$. lunata $(39.86 \%)$, followed by A. zinniae (36.62 \%), F. oxysporum (33.01\%), A. solani $(32.80 \%)$ and minimum $24.35 \%$ against $R$. solani. Ghosh et al. (2005) also reported antifungal activity of the crude extracts of gametophyte and sporophytes of Adiantum capillus-veneris L. and Adiantum lunulatum against Aspergillus niger and Rhizopus stolonifer.

The statistical analysis of the data revealed that at $5 \%$ level of significance, in comparison to control, each phytoextract significantly inhibited the growth of tested pathogens. Although the percent growth inhibition increased with the concentration of extract (5-20\%) but difference was nonsignificant within the tested levels, viz. 5-10\%, 10$15 \%$ and $15-20 \%$ ).

A number of antifungal compounds of diverse skeletal patterns have been found in the plants. These compounds belong mainly to six broad chemical groups, such as phenolics and phenolic acids, coumarins and pyrones, flavonoids, isoflavonoids, steroids and steroidal alkaloids, and other miscellaneous compounds (Mitra et al., 1984). However, only a few commercial products from the plant are being used in practical plant protection.

The fungitoxic effects of the phyto-extracts indicate the potential of selected plant species as a source of natural fungicidal material. Antifungal activity was confirmed by all of the selected plant species and the results revealed that different plant extracts varied in their efficacy for inhibiting the mycelial growth of tested pathogens. Although the selected concentration of tested plant species was unable to completely inhibit the pathogens but they could be used in combination with the fungicides as IPM strategy to minimize the use of fungicides. The finding of the present investigation could be an important step towards the possibilities of using natural plant products as pesticides in the plant disease control. 


\section{REFERENCES}

Akinbode, O. A. and Ikotun, T. (2008), Evaluation of some bioagents and botanicals in in vitro control of Colletotrichum destructivum. Afr. J. Biotechnol., 7, 868-872.

Bajwa, R. and Ramzan, S. (2004), Antifungal activity of leaf extracts of some medicinal herbs against Aspergilli. Mycopath., 2, 101-106.

Bajwa, R., Shafique, S., Anjum, T. and Shafique, S. (2004), Antifungal Activity of Allelopathic Plant Extracts IV: Growth Response of Drechslera hawaiiensis, Alternaria alternata and Fusarium monilifrome to Aqueous Extract of Parthenium hysterophorus. Int. J. Agri. Biol., 6: 511-516.

Bandara, B. M. R., Kumar, N. S. and Samaranayake, K. M. S. (1989), An antifungal constituent from the stembark of Butea monosperma. J. Ethnopharmacol., 25, 73-75.

Choi, G. J., Jang, K. S., Kim, J. S, Lee, S.W., Cho, J. Y., Cho, K. Y. and Kim, J. C. (2004), In vivo antifungal activities of 57 plant Extracts against six plant pathogenic fungi. Plant Pathol. J., 3, 184-191.

Ghosh, P. G., Mukhopadhyay, R. and Gupta, K. (2005), Antifungal activity of the crude extracts and extracted phenols from gametophytes and sporophytes of two species of Adiantum. Taiwania, 4, 272-283.

Hadizadeh, Peivastegan B. and Kolahi, M. (2009), Antifungal activity of nettle (Urtica dioica L.), colocynth (Citrullus colocynthis L. Schrad), oleander (Nerium oleander L.) and konar (Ziziphus spinachristi L.) extracts on plants pathogenic fungi. Pak. $J$. Biol. Sci., 1, 58-63.

Harlapur, S. I., Kulkarani, M. S., Wali, and Kulkarani, M. C., S. (2007), Evaluation of plant extracts, bioagents and fungicides against Exserohilum turcicum (Pass.) Leonard and Suggs. causing turcicum leaf blight of maize. Karnataka J. Agric. Sci., 3, 541-544.

Khafagi, I. K. and Dewedar, A. (2000), The efficiency of random versus ethno-directed research in the evaluation of sinai medicinal plants for bioactive compounds. J. Ethnopharmacol., 71, 365 - 376.

Kim, D. I., Park, J. D., Kim, S. G., Kuk, H., Jang, M. J., and Kim, S. S. (2005), Screening of some crude plant extracts for heir acaricidal and insecticidal efficacies. J. Asian Pacific Entomol., 8, 93-100.

Mahadevan, A. (1982), Biochemical aspects of plant disease resistance. In- Part I: Performed inhibitory substances.: Today and Tomorrowos Printers and Pub. New Delhi pp 425-431.
Maji, M. D., Chattopadhyay, S., Kumar, P. and Saratchandra, B. (2005), In vitro screening of some plant extracts against fungal pathogens of mulberry (Morus spp.). Arch. Phytopathol. Pfl., 3, 157-164.

Manoharachary, C. and Gourinath, A. (1988), Effects of plant extracts on four pathogenic fungi. Papers presented in $5^{\text {th }}$ International Congress of Plant Pathology Kyoto, Japan.

Mitra, S. R., Choudhuri, A. and Adityachaudhury, N. (1984), Production of antifungal compounds by higher plants-a review of recent researches. Plant Physiol. Biochem., 11, 53-77.

Navie S. C., McFadyen R. E., Panetta F. D., and Adkins, S. W. (1996), The biology of Australian weeds 27. Parthenium hysterophorus L. Plant Prot. Quart., 11, 76-88.

Nduagu, C. Ekefan, E. J. and Nwankiti, A. O. (2008), Effect of some crude plant extracts on growth of Colletotrichum capsici (Synd) \& Bisby, causal agent of pepper anthracnose. J. Appl. Biosci., 2, 184-190.

Oluwalana, S. A., and Adekunle, M. F. (1998), Forest plant roots in household nutrition and health care in Abeokuta, Ogun State. Nigeria J. Trop. For. Resources, 1, 120-136.

Oluwalana, S. A., Adetoro, N. A., Adekunle M. F., and Momoh, S. (1999), The use of boipesticides in indigenous cropping systems in Ogun State Nigeria. Bioprospector, 2, 1-10.

Patni, C. S. and Kolte, S. J. (2006), Effect of some botanicals in management of Alternaria blight of rapeseed-mustard. Ann. Pl. Prot. Sci., 1, 151-156.

Robertson, L. N., and Kettle, B. A. (1994), Biology of Pseudoheteronyx sp. (Coleoptera: Scarabaeidae) on the central highlands in Queensland. J. Aust. Entomol. Soc., 33, 181-184.

Roy, B. and Dutta, B. K. (2003), In vitro lethal efficacy of leaf extract of Cannabis sativa Linn on the larvae of Chironomous samoensis Edward: an insect of public health concern. Indian J. Exp. Biol. Nov., 11, 1338-41.

Sharma N. and Trivedi, P. C. (2002), Screening of leaf extracts of some plants for their nematicidal and fungicidal properties against Meloidogyne incognita and Fusarium oxysporum. Asian J. Exp. Sci., 16, 2128

Singh, R. K. and Dwivedi, R. S. (1987). Effect of oils on Sclerotiumn rolfsii causing root rot of barley. Ind. J. Phytopath., 40, 531-533.

Srivastava, A. K. and Lal, B. (1997), Studies on biofungicidal properties of leaf extract of some plants. Indian phytopath., 3, 408-411. 
Strange, R. N., and Scott, P. R. (2005). Plant diseases: a threat to global food security. Annu. Rev. Phytopathol., 43, 83-116.

Varma, J. and Dubey, N. K. (1999), Prospectives of botanical and microbial products as pesticides of Tomorrow. Curr. Sci., 76, 172-179.
Vincent, J. M. (1927), Distortion of fungal hyphae in the presence of certain inhibitors. Nature 850pp.

Yasmin, M, Hossaini, K.S. and Bashar, M.A. (2008), Effect of some angiospermic plant extracts on in vitro vegetative growth of Fusarium Moniliforme. Bangladesh J. Bot., 1, 85-88. 